BMC

Public Health

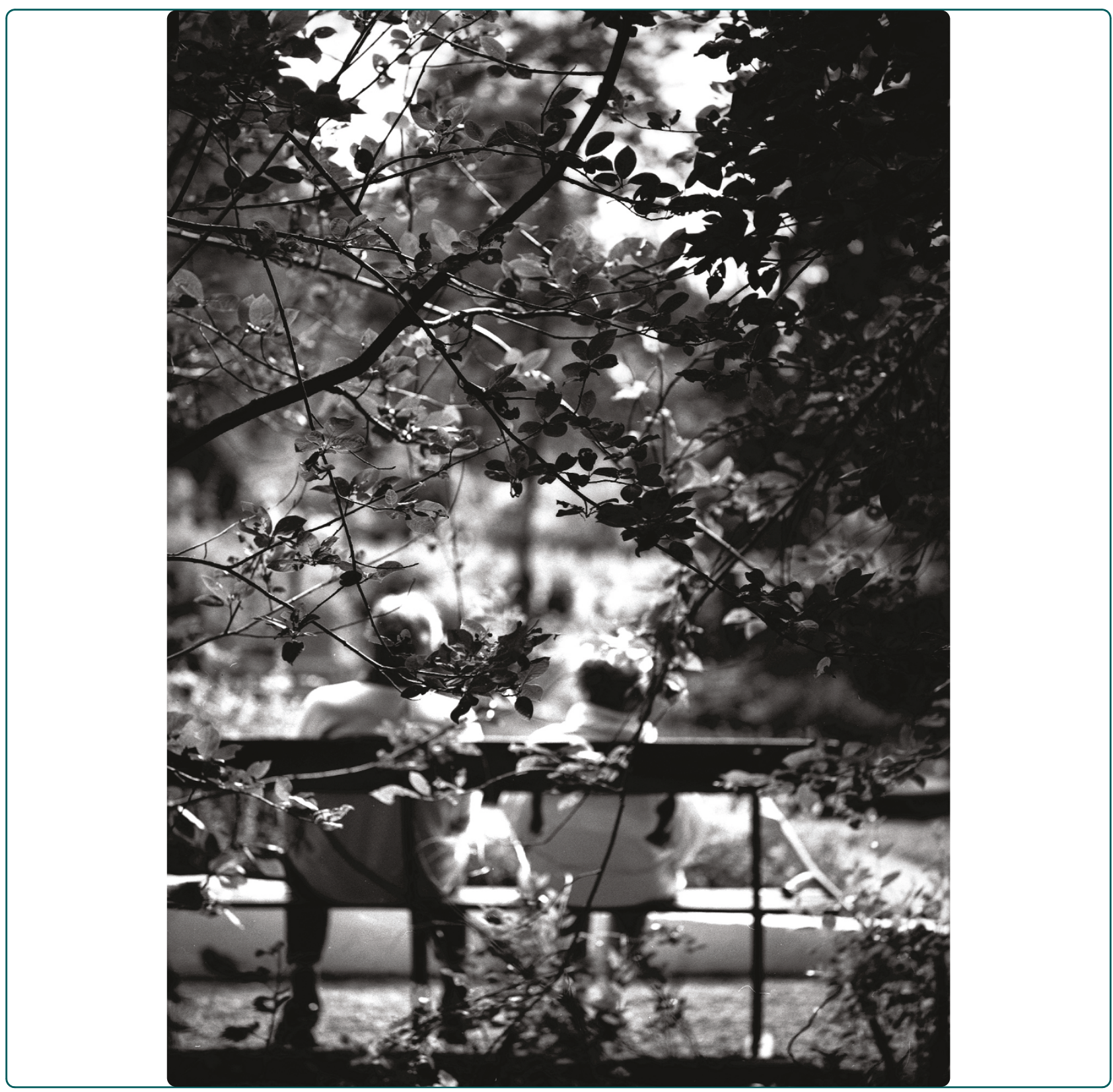

Determinants of self-rated health in old age: A population-based, cross-sectional study using the International Classification of Functioning

Arnadottir et al. 


\title{
Determinants of self-rated health in old age: A population-based, cross-sectional study using the International Classification of Functioning
}

\author{
Solveig A Arnadottir ${ }^{1,2^{*}}$, Elin D Gunnarsdottir ${ }^{3}$, Hans Stenlund ${ }^{4}$ and Lillemor Lundin-Olsson ${ }^{1}$
}

\begin{abstract}
Background: Self-rated health (SRH) is a widely used indicator of general health and multiple studies have supported the predictive validity of SRH in older populations concerning future health, functional decline, disability, and mortality. The aim of this study was to use the theoretical framework of the International Classification of Functioning, Disability and Health (ICF) to create a better understanding of factors associated with SRH among community-dwelling older people in urban and rural areas.

Methods: The study design was population-based and cross-sectional. Participants were 185 Icelanders, randomly selected from a national registry, community-dwelling, 65-88 years old, 63\% urban residents, and 52\% men. Participants were asked: "In general, would you say your health is excellent, very good, good, fair, or poor?" Associations with SRH were analyzed with ordinal logistic regression. Explanatory variables represented aspects of body functions, activities, participation, environmental factors and personal factors components of the ICF.

Results: Univariate analysis revealed that SRH was significantly associated with all analyzed ICF components through 16 out of 18 explanatory variables. Multivariate analysis, however, demonstrated that SRH had an independent association with five variables representing ICF body functions, activities, and personal factors components: The likelihood of a better SRH increased with advanced lower extremity capacity (adjusted odds ratio [adjOR] $=1.05, p<0.001$ ), upper extremity capacity (adjOR $=1.13, p=0.040$ ), household physical activity (adjOR $=$ $1.01, p=0.016$ ), and older age (adjOR $=1.09, p=0.006$ ); but decreased with more depressive symptoms (adjOR $=$ $0.79, p<0.001)$.
\end{abstract}

Conclusions: The results highlight a collection of ICF body functions, activities and personal factors associated with higher SRH among community-dwelling older people. Some of these, such as physical capacity, depressive symptoms, and habitual physical activity are of particular interest due to their potential for change through public health interventions. The use of ICF conceptual framework and widely accepted standardized assessments should make these results comparable and relevant in an international context.

\section{Background}

In 1982, Mossey and Shapiro [1] presented research results revealing that an older person's perception of his or her own health was an important predictor of sevenyear survival. Since then, a single-item scale of self-rated health (SRH) has become a widely used indicator of general health and multiple studies have further supported the predictive validity of SRH in older

\footnotetext{
* Correspondence: saa@unak.is

'Department of Community Medicine and Rehabilitation, Division of

Physiotherapy, Umeå University, Sweden

Full list of author information is available at the end of the article
}

populations concerning future health, functional decline, disability, and mortality [2-6]. Based on this research and that of others, Jylhä [7] described SRH as an active cognitive process that is not guided by formal, agreed rules or definitions of health. She further portrayed it as an individual and subjective conception that is related to the strongest biological indicator, death, and constitutes a crossroad between the social world and psychological experiences on the one hand, and the biological world, on the other. Therefore, in its simplicity, the answer to the SRH question "would you say your health in general is excellent, very good, good, fair, or poor?" may

\section{C) Biomed Central}


summarize the dimensions of health that are most meaningful to each individual $[8,9]$. Hence, SRH has been described as one of the most important clientoriented health outcomes available [10] and recommended as a tool for disease risk screening [11], as an outcome indicator in the primary care [10], and standard part of clinical trials [12].

Research indicates that the relationship of SRH to important aspects of older people's health, such as disability and chronic diseases, is one of mutual influence rather than direct causality [8]. To understand such a complex interrelationship, a firm theoretical approach would be beneficial. The World Health Organization's International Classification of Functioning, Disability and Health (ICF) model was developed to provide a unified standard language and conceptual framework for the description of health and health-related states from a biopsychosocial point of view [13]. Thus, the ICF facilitates interdisciplinary thinking and may help to translate a holistic vision of health into practice by identifying potentially influential factors that are within the scope of public health initiatives.

Although perceptions of health are not included in the ICF framework, multiple variables within various ICF components represent the body and the person in context and may play an important role in older persons' self ratings of health. For example, ICF term disability refers to limitations and restrictions related to a health problem while SRH may reflect the personal value given to these limitations and restrictions [14]. Therefore, if a certain activities limitation is highly meaningful to an older individual it may lead to poor self-ratings of health. Moreover, a public health intervention that results in higher SRH may emphasize the client centeredness of that intervention's effect.

Paying more attention to the environment and the person-environment interactions is among the main challenges within current research on aging and health [15]. One of the most obvious environmental factors in the life of an older person is his or her place of residency. Residency in urban versus rural communities is an example of value-loaded contextual factor which, apart from an often large proportion of older people in the community [16], reflects e.g. population density, type of work, physical geography, access to health service, transportation services, and social norms $[17,18]$. All these aspects of residency may potentially affect health and perceptions of health. Therefore, urban versus rural residency should not be overlooked when studying health and health-related states in older populations.

SRH provides client-centered information on the complex matter of general health through simple and inexpensive means $[14,19]$. Our study objective was to identify determinants of high SRH among older people in urban and rural areas, using standardized scales and nonstandardized sociodemographic questions, internationally known in the context of aging and health. We applied the theoretical framework of ICF throughout our study, to facilitate a focused approach and to expand our understanding of what is important for higher self-ratings of health.

\section{Methods}

\section{Participants and procedure}

The current study was a part of a cross-sectional, population-based research among older community-dwelling Icelanders [20]. Study participants were randomly selected from the national registry of one urban and two adjacent rural geographical clusters in northern Iceland (Figure 1). The urban study area was a university town and the second largest urban municipality in Iceland after the Greater Reykjavík capital area. It had approximately 16.500 inhabitants and of these $12 \%$ had reached 65 years of age. Of this older age group, about $88 \%$ were registered as community-dwelling, and of these approximately $44 \%$ were men. In this urban area there was no more than 200 meters between houses, and inhabitants earned their living from sources other than farming. The rural area is separated geographically from the urban study area by a fjord and a mountain range. In total, it had approximately 1000 inhabitants, $18 \%$ of them had reached 65 years of age, and of these $56 \%$ were men. As there was no institution for older people in the municipality, everybody was registered as community-dwelling. The inhabitants lived on farms or in other isolated houses and the majority earned their living by farming.

The inhabitants of these urban and rural areas were eligible for participation in the study if they were: (1) at least 65 years of age, (2) community-dwelling, and (3)

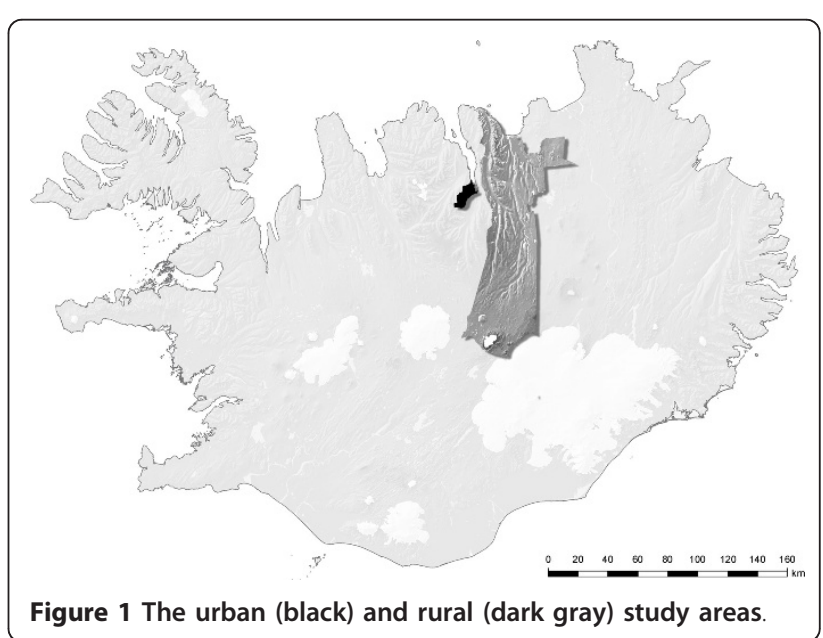


able to communicate verbally over a phone and set up a meeting time with a research assistant. After randomly selecting 250 individuals who fulfilled the inclusion criteria, these potential participants were approached by letter and then by phone a few days later and asked to participate in the study. Fourteen of the 250 potential participants did not fulfill the inclusion criteria and were therefore not asked to participate: seven had recently moved into an institution, five could not communicate verbally according to a caregiver, and two were inaccessible. Of the 236 persons who fulfilled the inclusion criteria, 50 declined to participate, and one person did not complete the SRH assessment battery. Therefore, the study sample comprised 185 participants (78.4\% participation rate). T-test and chi-square statistics revealed that the 50 people who declined to participate did not differ significantly from the participants with regard to age $(p=0.258)$, gender $(p=0.985)$, or residency $(p=0.738)$. The reasons they gave for not participating included not having time, being opposed to research, being too young and healthy, and being too old and sick. The person who did not complete the assessment battery was a rural man.

The study was approved by The National Bioethics Committee (04-037-S1) and reported to The Data Protection Authorities (S1948/2004). Data were collected in June through September 2004. Written informed consent was obtained from all participants. Before data collection, three research assistants were trained in the administration of the assessment battery. Participants had a choice between meeting the research assistants in the participant's home or at a research base near their home. The assessment battery was based on self-reports and administered in a face-to-face interview format, with the exception of one performance test of basic mobility and a test of cognitive function. The participants were shown, in an enlarged font, the response options for each question to facilitate the interview among participants with hearing impairment. All data were collected in one visit which lasted from one to three hours.

\section{Assessments}

Self-rated health was the outcome variable in our study. Participants were asked the question: "In general, would you say your health is excellent, very good, good, fair, or poor?". This version of the SRH question is the most widely used in the US and it was included as the first question in the well-known Short Form 36-item Health Survey (SF-36) [21].

Table 1 introduces the explanatory variables in the assessment battery and how they were grouped into the five ICF conceptual components: body functions, activities, participation, personal factors, and environmental factors. These explanatory variables were assessed with standardized scales and nonstandardized sociodemographic questions which all have shown to be relevant for aging research and practice and have a potential relationship with $\mathrm{SRH}$ in old age. The standardized scales have specific protocols for administration and implementation, they are scored on an ordinal or an interval scale, and they have been evaluated for psychometric properties in the general older population: Geriatric Depression Scale [22], Mini-Mental State Examination [23], Activities-Specific Balance Confidence Scale [24], Timed Up \& Go test [25], Bodily Pain subscale of SF-36 [26], Late-Life Function and Disability Instrument $[27,28]$, and Physical Activity Scale for the Elderly [29,30].

All explanatory variables were systematically linked to the ICF components using updated ICF linking rules from 2005 [14] by: (1) identifying the main aim and the meaningful concepts within each assessment, (2) linking these aims and concepts to the most appropriate ICF categories following steps that are thoroughly described in the linking rules, and (3) using the ICF categories to place each assessment within an ICF component.

\section{Data analyses}

Descriptive statistics for participants' characteristics were summarized by use of means, standard deviations and ranges for continuous data and counts and proportions for categorical data. Sampling weights were applied in inferential statistics to adjust for the uneven proportion of participants selected from the urban (8.6\%) and rural $(51.7 \%)$ population clusters.

Ordinal logistic regression was used to examine how variables representing aspects of ICF components were associated with the five rating scale categories of SRH (1 = poor, 2 = fair, 3 = good, 4 = very good, 5 = excellent). To deal with skewed continuous explanatory variables, we log-transformed PASE-leisure, and used a modified interval scale version of the ABC [31]. Scales with extremely skewed distribution of scores were dichotomized: 1) PASE-work into no physical work (PASE-work score = zero) and physical work (PASE-work score above zero = one), and 2) participation restriction (weighted median score $=83$ ) into more participation restriction (score of $0-82=$ zero) and less participation restriction (score of 83-100 = one).

Univariate ordinal logistic regression analysis was used to provide unadjusted odds ratios (OR) to determine the relationship between $\mathrm{SRH}$ and each of the explanatory variables. Then we used a full multivariate ordinal logistic regression model to provide the adjusted OR (adjOR) to determine the independent relationship between SRH and all the explanatory variables. Finally, we established a minimal multivariate ordinal logistic model which 
Table 1 Variables used to explain self-rated health in older people

\begin{tabular}{|c|c|c|}
\hline ICF component and definition & Variable & Scale \\
\hline \multirow{4}{*}{$\begin{array}{l}\text { Body Functions: Physiological functions } \\
\text { (including mental functions) of body systems. }\end{array}$} & Pain & Bodily Pain subscale of SF-36, interval scale $(0-100)^{\S}$, higher score = less pain. \\
\hline & $\begin{array}{l}\text { Depressive } \\
\text { symptoms }\end{array}$ & $\begin{array}{l}\text { Geriatric Depression Scale, ordinal scale (0-30), higher score = more depressive } \\
\text { symptoms. }\end{array}$ \\
\hline & Cognitive function & $\begin{array}{l}\text { Mini-Mental State Examination, ordinal scale (0-30), higher score = better } \\
\text { cognitive function }\end{array}$ \\
\hline & $\begin{array}{l}\text { Balance } \\
\text { confidence }\end{array}$ & $\begin{array}{l}\text { Activities-Specific Balance Confidence Scale, ordinal scale (0-100), higher score } \\
=\text { more self-reported balance confidence in } 16 \text { daily activities of greater or } \\
\text { lesser challenge during position changes or walking. }\end{array}$ \\
\hline \multirow[t]{4}{*}{$\begin{array}{l}\text { Activities: Execution of tasks or actions by an } \\
\text { individual. }\end{array}$} & Timed mobility & $\begin{array}{l}\text { Timed Up \& Go test, interval scale (time in sec.), higher score = worse/slower } \\
\text { performance in standing up from a chair, walking three meters, turning, } \\
\text { walking back to the chair and sitting down. }\end{array}$ \\
\hline & $\begin{array}{l}\text { Basic lower } \\
\text { extremity capacity }\end{array}$ & $\begin{array}{l}\text { LLFDI: Basic Lower Extremity Functioning, interval scale }(0-100)^{*} \text {, higher score }= \\
\text { more self-reported capacity in } 14 \text { activities that involve standing, stooping, and } \\
\text { fundamental walking. }\end{array}$ \\
\hline & $\begin{array}{l}\text { Advanced lower } \\
\text { extremity capacity }\end{array}$ & $\begin{array}{l}\text { LLFDI: Advanced Lower Extremity Functioning, interval scale (0-100*) , higher } \\
\text { score = more self-reported capacity in } 11 \text { activities that involve a high level of } \\
\text { physical ability and endurance. }\end{array}$ \\
\hline & $\begin{array}{l}\text { Upper extremity } \\
\text { capacity }\end{array}$ & $\begin{array}{l}\text { LLFDI: Upper Extremity Functioning, interval scale }(0-100)^{*} \text {, higher score }=\text { more } \\
\text { self-reported capacity in } 7 \text { activities that involve hands and arms. }\end{array}$ \\
\hline \multirow[t]{2}{*}{$\begin{array}{l}\text { Participation: Person's involvement in a life } \\
\text { situation. }\end{array}$} & $\begin{array}{l}\text { Participation } \\
\text { frequency }\end{array}$ & $\begin{array}{l}\text { LLFDI: Frequency Dimensiont, interval scale }(0-100)^{*} \text {, higher score }=\text { more self- } \\
\text { reported frequency of participation in } 16 \text { life situations. }\end{array}$ \\
\hline & $\begin{array}{l}\text { Participation } \\
\text { restriction }\end{array}$ & $\begin{array}{l}\text { LLFDI: Limitation Dimension, interval scale }(0-100)^{*} \text {, higher score }=\text { more } \\
\text { perceived restrictions for participating in } 16 \text { life situations. }\end{array}$ \\
\hline \multirow[t]{6}{*}{$\begin{array}{l}\text { Personal factors: Particular background of an } \\
\text { individual's life and living. }\end{array}$} & $\begin{array}{l}\text { Leisure-time } \\
\text { physical activity }\end{array}$ & $\begin{array}{l}\text { PASE-leisure, ordinal scale }(0-400+)+\text {, higher score }=\text { more energy spent in self } \\
\text { reported leisure-time activities e.g. walk, exercise, sport or recreation. }\end{array}$ \\
\hline & $\begin{array}{l}\text { Household } \\
\text { physical activity }\end{array}$ & $\begin{array}{l}\text { PASE-home, ordinal scale }(0-171)+\text {, higher score }=\text { more energy spent in self- } \\
\text { reported light and heavy housework, home repairs, lawn work, gardening or } \\
\text { caring for another person. }\end{array}$ \\
\hline & $\begin{array}{l}\text { Work-related } \\
\text { physical activity }\end{array}$ & $\begin{array}{l}\text { PASE-work, ordinal scale }(0-400+)+\text {, higher score }=\text { more energy spent in self- } \\
\text { reported work for pay or as a volunteer. }\end{array}$ \\
\hline & Medical Diagnoses & $\begin{array}{l}\text { Medical diagnoses, interval scale (sum of diagnoses), higher number of self- } \\
\text { reported medical diagnoses. }\end{array}$ \\
\hline & Age & Age, interval scale (years), obtained from the national registry. \\
\hline & Gender & Gender, nominal scale $(0-1), 0=$ woman and $1=$ man. \\
\hline \multirow{2}{*}{$\begin{array}{l}\text { Environmental factors: Physical, social and } \\
\text { attitudinal environment. }\end{array}$} & Residency & Residency, nominal scale $(0-1), 0=$ rural and $1=$ urban. \\
\hline & $\begin{array}{l}\text { Adequacy of } \\
\text { income }\end{array}$ & $\begin{array}{l}\text { Adequacy of income, ordinal scale }(0-1) \text {, higher score }=\text { income perceived as } \\
\text { adequate to fulfill daily needs. }\end{array}$ \\
\hline
\end{tabular}

${ }^{\S} \mathrm{SF}-36=$ The SF-36 ${ }^{\circledR}$ Health Survey is a generic measure of health status which has summary scales on physical and mental health. The physical health summary integrates outcomes from scales for physical functioning, physical role, bodily pain and general health.

*LLFDI = Late-Life Function and Disability Instrument is based on the Nagi's disability framework, yet it has been used with promising results to measure ICF's participation and activities. The LLFDI function domain contains three subscales that can measure activities in upper and lower extremities. The LLFDI disability domain includes two subscales that may be used to measure participation.

${ }^{\text {TPASE }}=$ The Physical Activity Scale for the Elderly is a self-report of physically active lifestyle in the past seven days. For the purpose of our analysis we divided the total PASE into three parts: PASE-leisure, PASE-home, and PASE-work. PASE scores are indicative of energy spent within each of these three habitual life domains and usually the total scores range from 0-400. Extremely active individuals can achieve even higher scores (400+).

included only variables that were significantly related to SRH (significance level set at $p=0.05$ ). This was done by removing insignificant variables from the full multivariate model, one by one, starting with the variables with the highest $p$ value. Ordinal logistic regression generates McFadden's pseudo $R^{2}$ values which we used to assist us in interpreting model fit at each step. The explanatory variables were measured on very different scales. Therefore, we calculated the likelihood of a better $\mathrm{SRH}$ per one standard deviation unit for each explanatory variable in the minimal multivariate model. Results were presented as OR, adjOR, 95\% CI and $p$ values.

The assumption of proportional odds for the multivariate models was examined using the Brant test and the results were non-significant (full model: $\chi^{2}=55.40$, $p=0.422$; minimal model: $\chi^{2}=22.16, p=0.075$ ), which indicates no differences in the proportionality of odds across the SRH response categories. Multicollinearity was tested by calculating variance inflation factors (VIF) 
for all explanatory variables in the full and the minimal multivariate model. The full model had all values of VIF $<4.5$ and the minimal model had all values of $\mathrm{VIF}<2.0$, and hence no problems were displayed. Stata 10.1 (Stata Corp LP, 4905 Lakeway Dr, College Station, TX 77845) was used for descriptive statistics, testing assumptions for ordinal logistic regression analyses, and inferential analyses on weighted data. SPSS 17.0 (SPSS Inc, $233 \mathrm{~S}$ Wacker Dr., Chicago, IL60606) was used for data screening and calculating VIF.

Finally, post hoc power analyses were completed to determine effect sizes of the study at $\alpha=0.05$ and power $=0.80$ using G*Power 3.0 for Windows (http:// www.psycho.uni-duesseldorf.de/aap/projects/gpower/). Our analyses yielded an effect size (Cohen's $f^{2}$ ) of 0.12 for the full multivariate model and 0.07 for the minimal multivariate model.

\section{Results}

Table 2 summarizes the characteristics of the 185 participants. Their age ranged from 65 to 88 years and all of them were white. One third of the sample was drawn from rural communities and the proportion of men was $52 \%$. Five percent reported no medical diagnosis, $30 \%$ reported one or two diagnoses, and $65 \%$ reported three or more diagnoses. The largest proportion rated their health as good (45\%), $37 \%$ as fair or poor, and $18 \%$ as very good or excellent.

The results of the univariate ordinal regression analyses are presented in Table 3a. The likelihood of having a better SRH, increased with scores indicating higher functioning on all the variables dealing with body functions, activities, and participation. The likelihood of a better SRH also increased with four variables representing ICF personal and environmental factors: a physically active lifestyle, fewer medical diagnoses, being a man and living in an urban area. Age and perceived adequacy of income were the only variables that did not have a significant univariate association with SRH. Older age, however, became significantly associated with a better SRH $(\mathrm{OR}=1.07,95 \% \mathrm{CI}=1.01-1.13, p=0.013)$ when we controlled for advanced lower extremity capacity. This significant association between age and SRH maintained its significance and even increased its strength in other multivariate models controlling for more variable than the advanced lower extremity capacity. The results from the full multivariate model are presented in Table $3 \mathrm{~b}$. While adjusting the model for the effects of all other variables, the likelihood of a better SRH increased with higher age and decreased with more depressive symptoms.

From the full multivariate model we created a minimal multivariate model. The minimal model included five variables representing aspects of ICF's body functions,
Table 2 Participant characteristics

\begin{tabular}{|c|c|}
\hline Variable & $\begin{array}{l}\text { Mean (SD) [range] or N } \\
(\%)^{\S}\end{array}$ \\
\hline \multicolumn{2}{|l|}{ Self rated health $(\mathrm{N}=185)$} \\
\hline Poor $=1$ & $14(7.6)$ \\
\hline Fair $=2$ & $55(29.7)$ \\
\hline Good $=3$ & $83(44.9)$ \\
\hline Very good $=4$ & $28(15.1)$ \\
\hline Excellent $=5$ & $5(2.7)$ \\
\hline \multicolumn{2}{|l|}{ Body Functions } \\
\hline Pain $=0-100$ & 65 (40.6) [0-100] \\
\hline Depressive symptoms $=0-30$ & $7(4.3)[1-20]$ \\
\hline Cognitive function $=0-30$ & $27(2.5)[16-30]$ \\
\hline Balance confidence $=0-100$ & $83(18.3)[21-100]$ \\
\hline \multicolumn{2}{|l|}{ Activities } \\
\hline Basic lower extremity capacity $=0-100$ & $76(15.5)[42-100]$ \\
\hline $\begin{array}{l}\text { Advanced lower extremity capacity }=0 \text { - } \\
100\end{array}$ & $56(17.3)[0-100]$ \\
\hline Upper extremity capacity $=0-100$ & $86(14.8)$ [43-100] \\
\hline Timed mobility = time in sec & $11(3.6)[5-24]$ \\
\hline \multicolumn{2}{|l|}{ Participation } \\
\hline Participation frequency $=0-100$ & $48(5.5)[33-67]$ \\
\hline Participation restriction $=0-100$ & $79(15.8)[42-100]$ \\
\hline \multicolumn{2}{|l|}{ Personal factors } \\
\hline Leisure-time physical activity $=0-400+$ & 18 (30.7) [0-254] \\
\hline Household physical activity = 0-171 & $78(41.1)[0-171]$ \\
\hline Work-related physical activity $=0-400+$ & $31(65.3)[0-420]$ \\
\hline Medical diagnoses, total number & $3(1.8)[1-8]$ \\
\hline Age $=$ years & $74(6.3)[65-88]$ \\
\hline \multicolumn{2}{|l|}{ Gender: } \\
\hline Woman $=0$ & $89(48.1)$ \\
\hline Man $=1$ & $96(51.9)$ \\
\hline \multicolumn{2}{|l|}{ Environmental factors } \\
\hline \multicolumn{2}{|l|}{ Residency: } \\
\hline Rural $=0$ & $67(36.2)$ \\
\hline Urban $=1$ & $118(63.8)$ \\
\hline \multicolumn{2}{|l|}{ Adequacy of income: } \\
\hline $\mathrm{No}=0$ & $62(33.5)$ \\
\hline Yes $=1$ & $123(66.5)$ \\
\hline
\end{tabular}

${ }^{5}$ Percentages (\%) are based on the actual number of participants for each variable. This actual number of participants was lower on the following variables due to missing data: cognitive function $(n=1)$, balance confidence $(n=2)$, timed mobility $(n=5)$, participation frequency $(n=1)$, and participation restriction $(n=1)$.

activities, and personal factors (Table 3c). In the minimal model, the likelihood of a better SRH increased with older age, household physical activity, advanced lower extremity capacity, and upper extremity capacity. However, this likelihood of a better SRH decreased with more depressive symptoms. Adjusting this minimal model for gender did not change the results. The pseudo $R^{2}$ values revealed almost the same strength of the relationship between SRH and the variables in the full model (pseudo $R^{2}=0.25$ ) and the minimal model 
Table 3 Relationships between self-rated health (SRH) and scores on explanatory variables*: a) univariate SRH models, 3b) full multivariate SRH model, and 3c) minimal multivariate model

\begin{tabular}{|c|c|c|c|c|c|c|c|c|c|c|}
\hline \multirow[t]{2}{*}{ Explanatory variable } & \multirow[b]{2}{*}{$\mathrm{N} \neq$} & \multicolumn{3}{|c|}{ 3a) Univariate } & \multicolumn{3}{|c|}{ 3b) Full multivariate model } & \multicolumn{3}{|c|}{ 3c) Minimal multivariate model } \\
\hline & & OR§ & $95 \% \mathrm{Cl}$ & $P$ & AdjOR & $95 \% \mathrm{Cl}$ & $P$ & AdjOR & $95 \% \mathrm{Cl}$ & $P$ \\
\hline \multicolumn{11}{|l|}{ Body Functions } \\
\hline Pain & 185 & 1.02 & $1.01-1.03$ & $<0.001$ & 1.01 & 0.99-1.02 & 0.134 & & & \\
\hline Depressive symptoms & 185 & 0.70 & $0.62-0.78$ & $<0.001$ & 0.82 & $0.68-0.97$ & 0.023 & 0.79 & $0.70-0.88$ & $<0.001$ \\
\hline Cognitive function & 184 & 1.19 & $1.03-1.39$ & 0.020 & 1.04 & $0.85-1.28$ & 0.688 & & & \\
\hline Balance confidence & 183 & 1.59 & $1.35-1.86$ & $<0.001$ & 1.12 & $0.79-1.56$ & 0.516 & & & \\
\hline \multicolumn{11}{|l|}{ Activities } \\
\hline Basic lower extremity capacity & 185 & 1.07 & $1.05-1.10$ & $<0.001$ & 0.98 & $0.92-1.03$ & 0.391 & & & \\
\hline Advanced lower extremity capacity & 185 & 1.06 & $1.04-1.09$ & $<0.001$ & 1.03 & $0.99-1.07$ & 0.057 & 1.05 & $1.02-1.17$ & $<0.001$ \\
\hline Upper extremity capacity & 185 & 1.07 & $1.05-1.09$ & $<0.001$ & 1.02 & $0.98-1.06$ & 0.251 & 1.13 & $1.00-1.16$ & 0.040 \\
\hline Timed mobility & 180 & 0.73 & $0.64-0.84$ & $<0.001$ & 0.89 & $0.72-1.11$ & 0.325 & & & \\
\hline \multicolumn{11}{|l|}{ Participation } \\
\hline Participation frequency & 184 & 1.13 & $1.03-1.22$ & 0.005 & 1.00 & $0.91-1.09$ & 0.995 & & & \\
\hline Less participation restriction & 184 & 6.66 & $3.22-13.8$ & $<0.001$ & 1.48 & $0.58-3.74$ & 0.411 & & & \\
\hline \multicolumn{11}{|l|}{ Personal factors } \\
\hline Leisure time PA† & 182 & 2.53 & $1.43-4.50$ & 0.002 & 1.16 & $0.57-2.31$ & 0.683 & & & \\
\hline Household PA & 185 & 1.02 & $1.01-1.03$ & $<0.001$ & 1.01 & $0.99-1.02$ & 0.064 & 1.01 & $1.00-1.02$ & 0.016 \\
\hline Work-related PA & 185 & 2.16 & $1.11-4.20$ & 0.024 & 1.30 & $0.61-2.77$ & 0.492 & & & \\
\hline Medical diagnoses & 185 & 0.55 & $0.46-0.66$ & $<0.001$ & 0.89 & $0.66-1.20$ & 0.448 & & & \\
\hline Age & 185 & 0.97 & $0.92-1.02$ & 0.250 & 1.10 & $1.03-1.18$ & 0.004 & 1.09 & $1.02-1.17$ & 0.006 \\
\hline Gender & 185 & 2.47 & $1.30-4.67$ & 0.006 & 0.85 & $0.37-1.92$ & 0.699 & & & \\
\hline \multicolumn{11}{|l|}{ Environmental factors } \\
\hline Residency & 185 & 2.17 & $1.25-3.76$ & 0.006 & 0.66 & $0.22-1.95$ & 0.454 & & & \\
\hline \multirow[t]{2}{*}{ Adequacy of income } & 185 & 1.13 & $0.56-2.27$ & 0.744 & 0.85 & $0.36-1.98$ & 0.709 & & & \\
\hline & & & & & \multicolumn{3}{|c|}{ Pseudo $R^{2}=0.25$} & \multicolumn{3}{|c|}{ Pseudo $R^{2}=0.24$} \\
\hline
\end{tabular}

*Based on weighted data; +PA = physical activity; $¥ \mathrm{~N}$ is less than 185 were data are missing on the explanatory variables; §Odds Ratios (OR) higher than one indicate that higher score on the explanatory variable is associated with better SRH.

(pseudo $\left.R^{2}=0.24\right)$. Figure 2, presents additional information on the likelihood of a better SRH per one standard deviation unit for each explanatory variable in the minimal multivariate model.

\section{Discussion}

Our results present how SRH is associated with all analyzed ICF components through 16 standardized scales

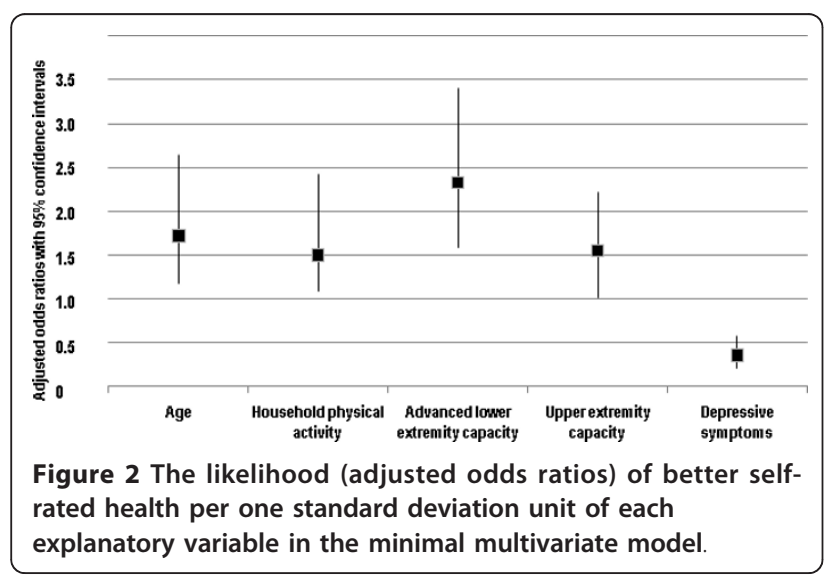

and nonstandardized sociodemographic questions which are commonly used in research on aging and health. Five variables categorized as ICF body functions, activities, and personal factors were independently associated with SRH. These variables were advanced lower extremity capacity, upper extremity capacity, depressive symptoms, household physical activity, and age. SRH had a weaker association with variables categorized as ICF participation and environmental factors.

To our knowledge, this study is the first to associate $\mathrm{SRH}$ in older people with advanced lower extremity capacity belonging to the activities component of ICF. The standardized scale (LLFDI) we used to measure it, involves a high level of physical ability and endurance [27] by including advanced activities (such as "running half a mile"), rarely in focus when assessing the functioning of older people. Poor SRH has, however, been associated with lower extremity disability measured with a rapid timed gait task in older community-dwelling urban people [32] and self-reported mobility difficulties in 50 years and older adults across 11 European countries [33]. Our results on the strong relationship between SRH and self reported upper extremity capacity 
supports existing understanding on the association between SRH and upper extremity performance in older people [34]. This is an important contribution, as selfreports of upper extremity capacity can reflect meaningful activities of the hands in a real life context, yet have not been of major interest when studying SRH in this age group. Moreover, our results confirmed a robust relationship between a worse SRH and depressive symptoms, which has been well described in other studies [33,35].

Habitual physical activity is yet another variable in our study, which in the literature is rarely associated with SRH. Although higher levels of physical activity have been presented as most significant predictors of SRH [33] these studies limit their focus to leisure-time physical activity. The PASE questionnaire used in our study, however, also acknowledges how energy can be spent through other aspects of daily behavior [29]. Although PASE was not originally designed to be partitioned, previous studies have provided informative results on physical activity in different life domains $[20,36]$. By analyzing the three sub-domains of PASE separately, we were able to introduce new information on how SRH in old age is associated with a physically active lifestyle related to leisure, household, and occupation. Studies with a broader perspective on health in old age and physical activity are much needed [20], as older people may be able to fill their health improving "physical activity quote" through other means than sports and recreational activities [37]. The strong association between SRH and household physical activity is a very good example of how the relationship between SRH and behavior or life-style may be based on an interrelationship rather than causality. An older person in good health may be more likely to independently take care of home chores. Likewise, physically demanding home chores may have a positive influence on an older person's health.

Participants reported the same perceived health status or better health status at ages where health is expected to decline and disabilities to rise. Apparently, less capacity in advanced lower extremity activities played an important role in keeping participants from rating their health even higher with age. Response Shift Theory [38], commonly used in disability studies, may explain this well known mismatch between the "internal" self-ratings of health and "external" assessments of health conditions in older cohorts [2,7]. According to this theory, although the older groups in our study may have had more disabilities and health conditions, their SRH may have been good as a result of: (1) a change in internal standards of how health is rated (e.g. through comparison with less healthy or institutionalized peers), (2) a change in values (e.g. take better care of one's health with age), or (3) a redefinition of what health really is. We can, however, not exclude the possibility that the oldest participants represent a group of survivors that lived longer as they have positive attitude towards life in general including their own health status [39]. Regarding gender, our results support other studies showing that women tend to rate their health lower than men $[4,40]$, and that this gender difference in SRH disappeared when actual health conditions are taken into account [33].

The strong association between SRH and variables that represent the older individual's personal characteristics, body functions, or activities is an interesting contribution to existing knowledge on SRH. Although one may expect the environment and participation (which strongly involves an environmental context) to have a stronger connection to SRH, our results are in accordance with a study on French and British working-age cohorts [41]. In that study, SRH was shown to have the firmest grounds in an individual's aspects of physical and mental health while environmental and other sociodemographic factors contributed less to SRH. Interestingly, the better SRH among our urban than rural participants contrasts with Canadian study results where SRH did not differ among community-dwelling seniors in urban, small towns, and rural areas [42]. Our residency-based difference in SRH, however, disappeared when the functioning of participants was taken into account. This indicates that, unlike the Canadian study, our study found an actual difference in the health status of older people in urban and rural communities.

Our study must be interpreted in light of some limitations. First, the study was cross-sectional and causality regarding the explanatory variables and SRH cannot be inferred. Second, the sample size was small, increasing the risk of type II error. The power of the study, however, was optimized by using continuous and more precise variables where possible. Third, our data collection took place in 2004 when most standardized assessments for older people were developed within another conceptual model than ICF. Therefore, we used the linking rules to select quality measurement tools that best matched the ICF framework and our study population. Creating such a crosswalk between ICF and the available assessments of functioning and health was a challenge which other researchers and practitioners have undoubtedly been facing in the last decade. Finally, generalizability of the results is affected by the fact that our randomly selected population-based sample was drawn in northern Iceland. Our participants rated their general health relatively low as compared to a 60 years and older random sample of non-institutionalized adults in the U.S. [43]. In this U.S. sample, $41 \%$ rated themselves as being in a very good or excellent health, $32 \%$ in good health and $27 \%$ in fair or poor health, as compared to our sample with $18 \%$ in very good or excellent health, 
$45 \%$ in good health, and $37 \%$ in fair or poor health. Such differences in SRH distributions between cultural and language regions have been seen within European countries and within ethnic groups in the U.S. and do have to be considered when generalizing research results on SRH $[7,33]$. These differences have been related to factors such as: (1) differences in the true multidimensional aspects of health, (2) differences in the process of health evaluation, (3) language and semantic issues, and (4) reporting style. Inevitably, there remains a need for future research aimed at replicating and extending the current findings with larger and more diverse samples.

Most of the variables that stand out in our study by their independent association with $\mathrm{SRH}$, are measuring constructs that are known to have good interventions potential. Therefore, it's worth noting some potential practical implications of these associations. Yet, as our cross-sectional study design does not allow us to claim causality the possibility of mutual influences remains. First, advanced lower extremity capacity and upper extremity capacity indicate individual physical capacity that may be improved [37]. In the context of compression of morbidity [44], older community-dwelling people today and in the future may have high internal standards regarding their functioning and health. They may base their self ratings of health on activities and participation that require more advanced physical capacity than usually is tested in traditional standardized assessments designed for older people. Therefore, public health professionals must account for such advanced activities and ambitious health goals in old age. Second, depressive symptoms played a large role in a worse $\mathrm{SRH}$. Depression is a treatable condition but if left untreated there is evidence of an increased risk of morbidity and mortality and an associated economic and societal burden [45]. Physical activity has been presented as one of the most important modalities to prevent and treat depression in the older population $[37,45,46]$. Third, household physical activity was indeed one of the variables independently associated with SRH in our research. This aspect of physical activity goes beyond the traditional focus on exercise and may be indicative of an important stepping stone toward optimizing perceived health. Moreover, many of the variables which were only associated with SRH in univariate models may be important in a practical context and direct us towards specific interventions to optimize perceptions of health in older clients and populations. For example, enhancing confidence in maintaining balance in daily activities or alleviating pain related to musculoskeletal impairments are potentially important links between physically active behavior and better perceptions of health in old age.

\section{Conclusions}

The results highlight a collection of body functions, activities and personal factors independently associated with higher SRH among community-dwelling older people. Some of these factors, such as advanced lower extremity and upper extremity physical capacity, depressive symptoms, and habitual physical activity pattern should be of particular interest to public health professionals, due to their potential for interventions which may positively influence SRH. The use of ICF conceptual framework and widely accepted standardized assessments, that have been used both in surveys and clinical settings, should make the results comparable and relevant in an international context and thereby contribute to a growing body of information applicable to address the challenges and opportunities of aging populations.

\section{Acknowledgements}

We thank the participants of the study for their time and effort. This research was supported by grants from the Icelandic Research Fund (050410031); the University of Akureyri Research Fund; the KEA University Fund; the Erik and Anne-Marie Detlof's Fundation, Umeå University; the JC Kempe Memorial Foundation; the Icelandic Physical Therapy Association; the Icelandic Gerontological Society; and the Icelandic Gerontological Council.

Figure 1 was prepared to this study by the National Land Survey of Iceland.

\section{Author details}

${ }^{1}$ Department of Community Medicine and Rehabilitation, Division of Physiotherapy, Umeå University, Sweden. ${ }^{2}$ School of Health Sciences, University of Akureyri, Iceland. ${ }^{3}$ School of Humanities and Social Sciences, University of Akureyri, Iceland. ${ }^{4}$ Department of Public Health and Clinical Medicine, Division of Epidemiology and Global Health, Umeå University, Sweden

\section{Authors' contributions}

SAA: Provided concept/idea/research design, acquisition of data, analysis of data, interpretation of data, and writing manuscript. EDG: Participated in concept/idea/research design, acquisition of data, and revising the manuscript. HS: Participated in analysis and interpretation of data and revising the manuscript. LLO: Participated in research design, analysis of data, interpretation of data, and revising the manuscript. All authors read and approved the final manuscript.

\section{Competing interests}

The authors declare that they have no competing interests.

Received: 13 May 2011 Accepted: 25 August 2011

Published: 25 August 2011

\section{References}

1. Mossey JM, Shapiro E: Self-rated health: a predictor of mortality among the elderly. Am J Public Health 1982, 72:800-808.

2. Jylhä M, Guralnik JM, Balfour J, Fried LP: Walking difficulty, walking speed, and age as predictors of self-rated health. J Gerontol A Biol Sci Med SC 2001, 56:M609-M617.

3. Lee $Y$ : The predictive value of self assessed general, physical, and mental health on functional decline and mortality in older adults. J Epidemiol Community Health 2000, 54:123-129.

4. Wilcox VL, Kasl SV, Idler EL: Self-rated health and physical disability in elderly survivors of a major medical event. J Gerontol B Psychol Sci Soc Sci 1996, 51B:S96-S104

5. Idler EL, Kasl SV: Self-ratings of health: Do they also predict change in functional ability? J Gerontol B Psychol Sci Soc Sci 1995, 50B:S344-S353. 
6. Lyyra T-M, Heikkinen E, Lyyra A-L, Jylhä M: Self-rated health and mortality: could clinical and performance-based measures of health and functioning explain the association? Arch Gerontol Geriatr 2006, 42:277-288.

7. Jylhä M: What is self-rated health and why does it predict mortality? Towards a unified conceptual model. Soc Sci Med 2009, 69:307-316.

8. Bailis DS, Segall A, Chipperfield JG: Two views of self-rated general health status. Soc Sci Med 2003, 56:203-217.

9. Idler EL, Hudson SV, Leventhal H: The meanings of self-ratings of health: a qualitative and quantitative approach. Res Aging 1999, 21:458-476.

10. Rohrer JE, Arif A, Denison A, Young R, Adamson S: Overall self-rated health as an outcome indicator in primary care. J Eval Clin Pract 2007, 13:882-888.

11. May M, Lawlor DA, Brindle P, Patel R, Ebrahim S: Cardiovascular disease risk assessment in older women: can we improve on Framingham? British Women's Heart and Health prospective cohort study. Heart 2006, 92:1396-1401.

12. Fayers PM, Sprangers MA: Understanding self-rated health. Lancet 2002, 359:187-188

13. World Health Organization: International Classification of Functioning Disability and Health Geneva: World Health Organization; 2001.

14. Cieza A, Geyh S, Chatterji S, Kostanjsek N, Ustun B, Stucki G: ICF linking rules: an update based on lessons learned. J Rehabil Med 2005, 37:212-218.

15. Wahl HW: Ageing research along the urban-rural distinction: old questions and new potential. Eur J Ageing 2005, 2:131-136.

16. Peters KE, Gupta S, Stoller N, Mueller B: Implications of the aging process: opportunities for prevention in the farming community. J Agromedicine 2008, 13:111-118.

17. Pullen C, Walker SN, Fiandt K: Determinants of health-promoting lifestyle behaviors in rural older women. Fam Community Health 2001, 24:49-72.

18. Higgs G: Investigating trends in rural health outcomes: a research agenda. Geoforum 1999, 30:203-221.

19. Greenspan Al, Wolf SL, Kelley ME, O'Grady M: Tai Chi and perceived health status in older adults who are transitionally frail: a randomized controlled trial. Phys Ther 2007, 87:525-535.

20. Arnadottir SA, Gunnarsdottir ED, Lundin-Olsson L: Are rural older Icelanders less physically active than those living in urban areas? A population-based study. Scand J Public Health 2009, 37:409-417.

21. Ware JE Jr, Gandek B: Overview of the SF-36 Health Survey and the International Quality of Life Assessment (IQOLA) Project. J Clin Epidemiol 1998, 51:903-912.

22. Yesavage $J A$, Brink $T L$, Rose $T L$, Lum $O$, Huang $V$, Adey M, Leirer VO: Development and validation of a geriatric depression screening scale: a preliminary report. J Psychiatr Res 1983, 17:37-49.

23. Folstein MF, Folstein SE, McHugh PR: "Mini-mental state". A practical method for grading the cognitive state of patients for the clinician. $J$ Psychiatr Res 1975, 12:189-198.

24. Myers AM: Program Evaluation for Exercise Leaders Champaign, IL, USA: Human Kinetics; 1999

25. Podsiadlo D, Richardson S: The timed "Up \& Go": a test of basic functional mobility for frail elderly persons. J Am Geriatr Soc 1991 39:142-148.

26. Brazier JE, Harper $\mathrm{R}$, Jones NM, O'Cathain A, Thomas KJ, Usherwood T, Westlake L: Validating the SF-36 health survey questionnaire: new outcome measure for primary care. BMJ 1992, 305:160-164.

27. Jette AM, Haley SM, Kooyoomjian JT: Late Life Function and Disability Instrument Manual Boston: Roybal Center for the Enhancement of Late-Life function; 2001.

28. Jette AM, Haley SM, Coster, Wendy J, Kooyoomjian JT, Levenson S, Heeren T, Ashba J: Late Life Function and Disability Instrument: I. Development and Evaluation of the Disability Component. J Gerontol A Biol Sci Med Sci 2002, 57:M209-M216.

29. Washburn RA, Smith KW, Jette AM, Janney CA: The Physical Activity Scale for the Elderly (PASE): development and evaluation. J Clin Epidemiol 1993, 46:153-162.

30. New England Research Institutes: PASE Physical Activity Scale for the Elderly administration and scoring instruction manual Watertown, MA, USA: New England Research Institutes; 1991

31. Arnadottir SA, Lundin-Olsson L, Gunnarsdottir ED, Fisher AG: Application of Rasch analysis to examine psychometric aspects of the Activities-Specific
Balance Confidence scale when used in a new cultural context. Arch Phys Med Rehabil 2010, 91:156-163.

32. Martinez DJ, Kasl SV, Gill TM, Barry LC: Longitudinal association between self-rated health and timed gait among older persons. J Gerontol B Psychol Sci Soc Sci 2010, 65:715-719.

33. Verropoulou G: Key elements composing self-rated health in older adults: a comparative study of 11 European countries. Eur J Ageing 2009, 6:213-226

34. Desrosiers J, Hébert R, Bravo G, Dutil E: Upper extremity performance test for the elderly (TEMPA): normative data and correlates with sensorimotor parameters. Arch Phys Med Rehab 1995, 76:1125-1129.

35. St John PD, Blandford AA, Strain LA: Does a rural residence predict the development of depressive symptoms in older adults? Can J Rural Med 2009, 14:150-156.

36. Dunlop DD, Semanik P, Song J, Sharma L, Nevitt M, Jackson R, Mysiw J, Chang RW: Moving to maintain function in knee osteoarthritis: evidence from the osteoarthritis initiative. Arch Phys Med Rehabil 2010, 91:714-721.

37. Nelson ME, Rejeski WJ, Blair SN, Duncan PW, Judge JO, King AC, Macera CA Castaneda-Sceppa C: Physical activity and public health in older adults: recommendation from the American College of Sports Medicine and the American Heart Association. Circulation 2007, 116:1094-1105.

38. Sprangers MAG, Schwartz CE: Integrating response shift into healthrelated quality of life research: a theoretical model. Soc Sci Med 1999, 48:1507-1515.

39. Ostir GV, Ottenbacher KJ, Markides KS: Onset of frailty in older adults and the protective role of positive affect. Psychol Aging 2004, 19:402-408.

40. McCullough ME, Laurenceau JP: Gender and the natural history of selfrated health: a 59-year longitudinal study. Health Psychol 2004, 23:651-655.

41. Singh-Manoux A, Martikainen P, Ferrie J, Zins M, Marmot M, Goldberg M: What does self rated health measure? Results from the British Whitehall II and French Gazel cohort studies. J Epidemiol Community Health 2006, 60:364-372.

42. St John PD, Blandford AA, Strain LA: Depressive symptoms among older adults in urban and rural areas. Int J Geriatr Psychiatry 2006, 21:1175-1180.

43. White AM, Philogene GS, Fine L, Sinha S: Social support and self-reported health status of older adults in the United States. Am J Public Health 2009, 99:1872-1878.

44. Fries JF: Aging, natural death, and the compression of morbidity. N Engl J Med 1980, 303:130-135

45. Blake H, Mo P, Malik S, Thomas S: How effective are physical activity interventions for alleviating depressive symptoms in older people? A systematic review. Clin Rehabil 2009, 23:873-887.

46. Kjellman B, Martinsen EW, Taube J, Andersson E: Depression. In Physical Activity in the Prevention and Treatment of Disease.. 2 edition. Edited by: Swedish National Institute of Public Health. Stockholm: Professional Associations for Physical Activity (Sweden); 2010:325-335.

\section{Pre-publication history}

The pre-publication history for this paper can be accessed here: http://www.biomedcentral.com/1471-2458/11/670/prepub

doi:10.1186/1471-2458-11-670

Cite this article as: Arnadottir et al:: Determinants of self-rated health in old age: A population-based, cross-sectional study using the International Classification of Functioning. BMC Public Health 2011 11:670. 